\title{
Clinical Management of Myopia in Adults: Treatment of Myopic CNV
}

\author{
Shaun Sim, Chee Wai Wong, and Gemmy C. M. Cheung
}

\section{Key Points}

- The prevalence of myopic choroidal neovascularization (CNV) was between $5.2 \%$ and $11.3 \%$ in individuals with pathological myopia and was more common in females.

- Fundus fluorescein angiography (FFA) and optical coherence tomography are the imaging modalities of choice to diagnose myopic CNV and assess activity.

- Current evidence supports the use of intravitreal anti-vascular endothelial growth factor as the gold standard of treatment for myopic CNV, following a pro re nata $(\mathrm{PRN})$ treatment regimen without a loading phase.

- Long-term visual outcomes remain less favorable, largely due to the development of chorioretinal atrophy around the regressed CNV.

\subsection{Disease Overview}

Myopic choroidal neovascularization (myopic CNV), a subtype of CNV associated with pathological myopia, is the second most common cause of CNV after age-related macular degeneration (AMD) $[1,2]$. Compared to CNV secondary to AMD, key differences include occurrence in a younger age group, less prominent exudative and hemorrhagic changes, generally smaller choroidal

S. Sim $\cdot$ C. W. Wong $\cdot$ G. C. M. Cheung $(\bowtie)$

Singapore National Eye Centre, Singapore, Singapore

Singapore Eye Research Institute, Singapore, Singapore

e-mail: gemmy.cheung.c.m@ singhealth.com.sg 
neovascular membranes, excellent response to anti-vascular endothelial growth factor treatment and better long-term visual prognosis [3-5]. It is one of the most sight-threatening complications of pathological myopia $[6,7]$, with individuals typically reporting acute loss of central vision. Estimated to develop in $5-10 \%$ of eyes with pathological myopia, myopic CNV is the most common cause of CNV in people aged 50 years or younger [1], with significant social and economic burden.

\subsection{Incidence and Prevalence}

Owing to a lack of uniform diagnostic criteria, the reported incidence and the prevalence of myopic CNV have varied widely and may be well underestimated. A recent systematic review reported that the prevalence of myopic CNV was between $5.2 \%$ and $11.3 \%$ in individuals with pathological myopia [8], with female preponderance seen in most studies [1, 2, 6, 9]. Myopic CNV was also bilateral in approximately $15 \%$ of individuals $[1,9]$. Table 13.1 shows the prevalence as reported in population-based studies and in individuals with pathological myopia.

Table 13.1 Prevalence of myopic CNV

\begin{tabular}{|c|c|c|c|c|c|}
\hline Reference & $\begin{array}{l}\text { Definition of } \\
\text { PM }\end{array}$ & $\begin{array}{l}\text { Definition of } \\
\text { CNV-type lesion }\end{array}$ & Age & $\begin{array}{l}\text { Subjects } \\
\text { (eyes) }\end{array}$ & $\begin{array}{l}\text { Prevalence of } \\
\mathrm{CNV}\end{array}$ \\
\hline \multicolumn{6}{|c|}{ Pathological myopia studies } \\
\hline $\begin{array}{l}\text { Curtin et al. } \\
\text { (1970) [9] }\end{array}$ & $\begin{array}{l}\mathrm{AL} \\
>26.5 \mathrm{~mm}\end{array}$ & Fuchs' spot & All ages & $(538)$ & $\begin{array}{l}5.2 \% \text {, bilateral in } \\
16.7 \%\end{array}$ \\
\hline $\begin{array}{l}\text { Grossniklaus } \\
\text { et al. (1992) } \\
{[10]}\end{array}$ & $\begin{array}{l}\text { AL } 25.5- \\
26.5 \mathrm{~mm}, \\
\text { refractive } \\
\text { error }-5.0 \text { to } \\
-7.5 \mathrm{D}\end{array}$ & $\begin{array}{l}\text { Subretinal } \\
\text { neovascu- } \\
\text { larization, } \\
\text { Fuchs'spot }\end{array}$ & All ages & $202(308)$ & $\begin{array}{l}5.2 \% \text {-subretinal } \\
\text { neovascularization } \\
3.2 \% \text {-Fuchs' } \\
\text { spot }\end{array}$ \\
\hline $\begin{array}{l}\text { Hayashi } \\
\text { et al. (2010) } \\
{[11]}\end{array}$ & $\begin{array}{l}\mathrm{AL} \geq 26.5 \mathrm{~mm} \\
\text { or refractive } \\
\text { error } \geq-8 \mathrm{D}\end{array}$ & $\mathrm{CNV}$ & All ages & $429(806)$ & $11.3 \%$ \\
\hline \multicolumn{6}{|c|}{ General population studies } \\
\hline $\begin{array}{l}\text { The Blue } \\
\text { Mountains } \\
\text { Eye Study }\end{array}$ & $\begin{array}{l}\text { "Myopic } \\
\text { retinopathy" }\end{array}$ & $\begin{array}{l}\text { CNV or Fuchs' } \\
\text { spot }\end{array}$ & $\geq 49$ years & $44(67)$ & $\begin{array}{l}6.0 \%-\mathrm{CNV} \\
1.5 \% \text {-Fuchs' } \\
\text { spot }\end{array}$ \\
\hline $\begin{array}{l}\text { The Beijing } \\
\text { Eye Study }\end{array}$ & $\begin{array}{l}\text { "Myopic } \\
\text { retinopathy" }\end{array}$ & Fuchs' spot & $\geq 40$ years & $132(198)$ & $1.5 \%$ \\
\hline
\end{tabular}

$P M$ pathological myopia, $A L$ axial length, $C N V$ choroidal neovascularization 


\subsection{Natural History}

The long-term outcome of CNV is poor if left untreated. In a 10-year follow-up study of 25 patients with myopic CNV, visual acuity deteriorated to 20/200 or worse in $89 \%$ and $96 \%$ of eyes in 5 and 10 years respectively [2]. Approximately $35 \%$ of individuals with myopic CNV in one eye developed CNV in the fellow eye, with a mean period of 8 years between eyes [12].

In the late twentieth century, Tokoro et al. classified myopic CNV into three stages; active, scar, and atrophic stages [13]. Several other authors subsequently examined longitudinally the natural course of CNV and the three stages associated with visual loss $[14,15]$. In the active phase, myopic CNV is characterized by hemorrhage with or without serous retinal detachment. In the scar phase, there is absorption of hemorrhage with development of fibrotic scars, some of which can become hyperpigmented, known classically as Fuchs' spots. Finally, in the atrophic phase, as the myopic CNV regresses, the development of macular chorioretinal atrophy ensues. Recent studies using swept source optical coherence tomography have revealed the presence of macular Bruch's membrane defect associated with myopic CNV. The expansion of these defects was found to be related to the enlargement of chorioretinal atrophy surrounding a regressed CNV [16]. In a small proportion of patients, poor visual outcome might be due to formation of myopic macular hole, particularly in eyes where chorioretinal atrophy is greater than one disc area [17].

\subsection{Risk Factors}

Compared to systemic risk factors, ocular risk factors have a much stronger influence on the development of myopic CNV. A prospective study found that eyes with myopic CNV had higher grade myopic maculopathy (with patchy retinal atrophy or worse) than eyes without myopic CNV. In the same series, eyes with higher grade myopic maculopathy were also 3.55 times more likely to develop myopic CNV than those with lower grade myopic maculopathy [18]. Higher grade lacquer cracks defined as crisscrossing lacquer cracks with or without linear cracks were also found in a significantly higher proportion of eyes with myopic $\mathrm{CNV}$ as compared to the fellow uninvolved eye $[19,20]$. Choroidal thinning, in particular the subfoveal and inferior choroid, was found to be significantly thinner in eyes with myopic CNV than in the fellow uninvolved eyes $[19,21]$. Furthermore, in patients with newly diagnosed myopic CNV, it was reported that the incidence of myopic CNV development in the fellow eye was $34.8 \%$ compared to $6.1 \%$ in those with no previous CNV [12]. Other studies have also established an association between highly myopic eyes with higher aqueous humor levels of the inflammatory cytokines interleukin 6 and $8[22,23]$. Systemic risk factors implicated in the development of myopic CNV include higher levels of C-reactive protein and complement factors $\mathrm{C} 3$ and $\mathrm{CH} 50$ [24]. Older age (>40 years), subfoveal CNV location, larger baseline lesion size 
( $>400 \mu \mathrm{m})$, and lower best corrected visual acuity (BCVA) at baseline have been identified as factors leading to poorer visual outcomes $[8,25]$.

\subsection{Pathogenesis}

The pathogenesis of myopic CNV has not been clarified although several theories have been proposed. The mechanical theory postulates that progressive elongation of the anteroposterior axis leads to breaks in the retinal pigment epithelium (RPE)Bruch's membrane-choriocapillaris complex with formation of lacquer cracks, which in turn facilitates neovascularization from choriocapillaris [26-28]. Lacquer cracks have been more frequently observed in fellow eyes of patients with unilateral myopic $\mathrm{CNV}$, hence the suggestion that breaks in Bruch's membrane as the predisposing factor for development of CNV in pathological myopia [12]. It has also been reported that in vitro, progressive elongation of the posterior pole results in mechanical stress of the RPE cell layer, thus upregulating the expression and secretion of angiogenic factors [29]. The increased expression of vascular endothelial growth factor (VEGF) in aqueous humor of eyes with myopic CNV compared to cataract controls has also been reported in a comparative study [22]. Notably, VEGF levels in myopic CNV were lower than those in CNV secondary to AMD and can be explained by the smaller size of CNV membranes in myopic CNV. It is the imbalance between pro-angiogenic and anti-angiogenic factors that results in the development of myopic CNV.

The heredo-degenerative theory has been supported by genetic factors associated with myopic CNV based on twin and familial aggregation studies of pathologic myopia [30]. In a recent study that analyzed 15 genes associated with age-related macular degeneration, it was found that a single nucleotide polymorphism in the complement factor I (CFI) gene was significantly associated with myopic CNV [31]. Complement factor I is a regulatory protein involved in three complement pathways and is expressed by macrophages, lymphocytes, and fibroblasts, suggesting that inflammation via the complement pathway may be involved in the development of myopic CNV.

The hemodynamic theory suggests that alterations in choroidal perfusion of myopic eyes with choroidal filling delay may result in choroidal ischemia [32]. This leads to subsequent upregulation of angiogenic factors and the subsequent development of myopic CNV [7]. Doppler ultrasound imaging of the retrobulbar vessels revealed significantly higher vascular flow resistance in the posterior ciliary artery in eyes with myopic CNV as compared to the fellow eye, thus further implicating dysfunction of choroidal circulation in the development of myopic CNV [33].

\subsection{Diagnosis and Monitoring}

On slit-lamp biomicroscopy, myopic CNV manifests as a small, flat, grayish subretinal lesion adjacent to or beneath the fovea [2, 6, 34, 35]. There may be associated macular hemorrhage with or without exudation or subretinal fluid. Spectral 

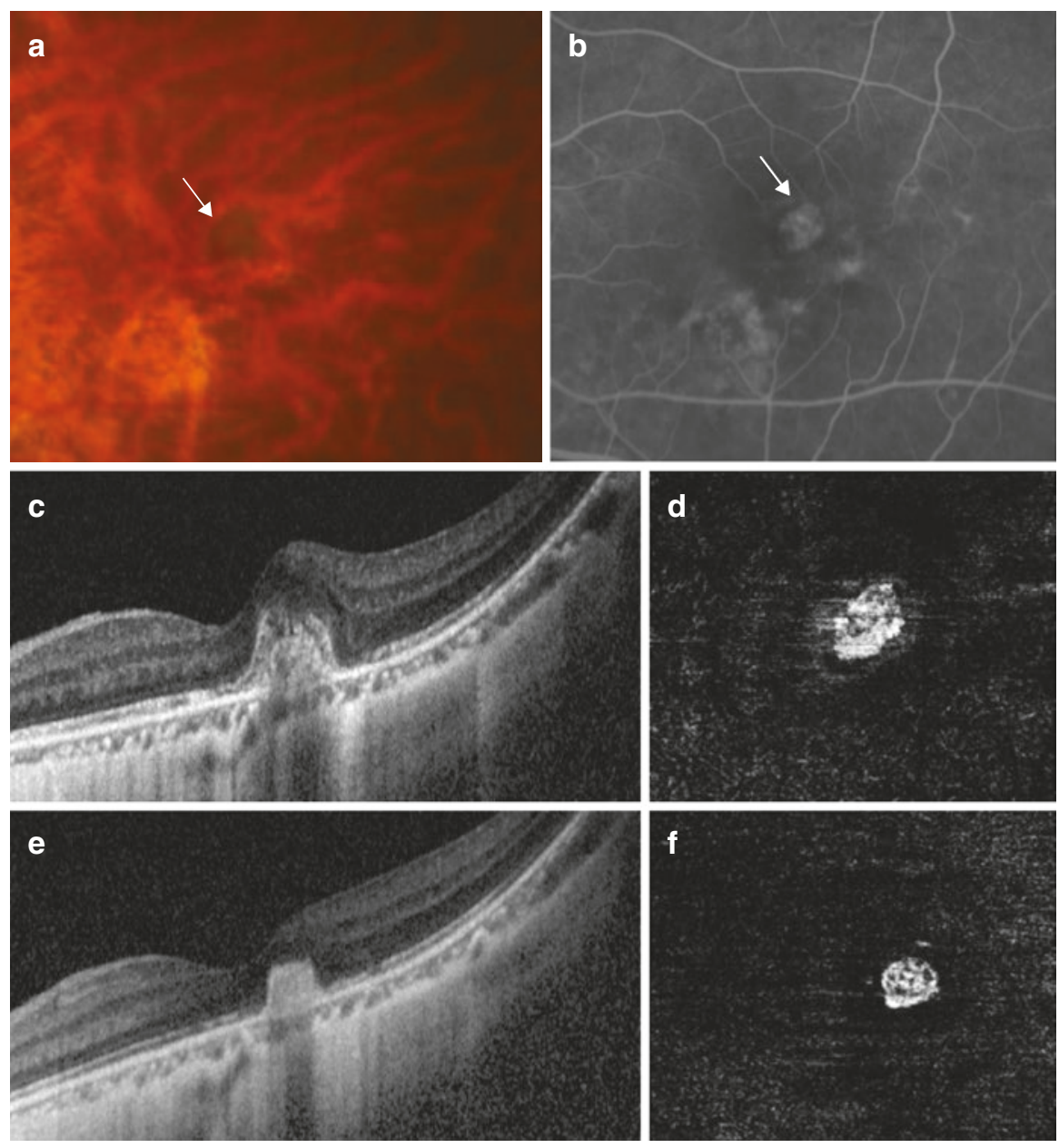

Fig. 13.1 Myopic CNV in a 57-year-old female. (a) Fundus photo shows a spot of subretinal hemorrhage (white arrow). (b) Fundus fluorescein angiogram shows early hyperfluorescence (white arrow) with a halo of hypofluoresence. (c) Optical coherence tomography (OCT) B scan shows a subretinal hyper-reflective lesion with indistinct margins, representing a type $2 \mathrm{CNV}$. (d) OCT angiography shows flow signals representing the choroidal neovascular membrane in the outer retina slab. (e) OCT B scan after treatment with a single intravitreal injection of anti-vascular endothelial growth factor. The subretinal hyper-reflective lesion is now inactive and has acquired well-demarcated margins. (f) OCT angiography shows persistence of flow signals despite inactivity

domain optical coherence tomography (SD-OCT) is a useful non-invasive screening tool that can be performed rapidly. On SD-OCT, myopic CNV presents as a hyperreflective material above the RPE band (type $2 \mathrm{CNV}$ ), with a variable amount of subretinal fluid (Fig. 13.1). OCT appearance is helpful to assess the activity of mCNV: signs of activity include ill-defined margins and disruption of the external 
limiting membrane, with a variable amount of intraretinal or subretinal fluid. As the lesion becomes inactive, it consolidates and acquires a distinct border.

Clinical diagnosis is confirmed by fundus fluorescein angiography (FFA). Most myopic CNVs are type 2 neovascularization and present with a "classic" pattern on fluorescein angiography (FA). The amount of leakage may vary, depending on the level of the activity, the size of the lesion and the health of the RPE. FA has been shown to have higher sensitivity for detecting the activity than OCT. In some eyes, subtle late leakage on FA may be the only sign of myopic CNV activity [35]. Myopic CNV with dense macular hemorrhage may result in masking of both early hyperfluorescence and late leakage. Indocyanine green angiography (ICGA) is useful in these cases to detect CNV. In addition, imaging also provides important prognostic indications. The size and location of the lesion can be better evaluated on FFA, while lacquer cracks and chorioretinal atrophy are best seen with ICGA [3]. ICGA also aids in exclusion of polypoidal choroidal vasculopathy (PCV) in those with macular hemorrhage, particularly important amongst Asian patients with the higher prevalence of PCV [36].

OCT angiography (OCTA) allows non-invasive imaging of the retinal and choroidal microvasculature. It is able to detect type $2 \mathrm{CNV}$ with high sensitivity and specificity when compared against FFA and ICGA [37]. OCTA is able to detect flow within myopic CNV vascular complexes and hence delineates vascular networks in these myopic neovascular membranes that lie above the RPE where flow signals are spared from attenuation [38]. On OCTA, CNV shape could be described as circular or irregular, margins could be well defined or poorly defined and appearance could be interlacing or tangled/disorganized vascular loops. In eyes with active myopic CNV lesions, the OCTA appearance is primarily interlacing, while inactive $\mathrm{CNV}$ neovascular networks appear primarily tangled [39-41]. OCTA is also able to clearly visualize the choriocapillaris in myopic eyes, with varying loss of choriocapillaris depending on the extent of myopic maculopathy and the presence of lacquer cracks [42, 43]. Although sensitivity and specificity compared to FFA as gold standard have not been fully evaluated for the diagnosis of myopic CNV, it is felt that OCTA may reduce the need for FFA if CNV is clearly visualized on OCTA at the commencement of anti-VEGF therapy. However, there remain limitations concerning OCTA: It is currently still unable to provide information on the disease activity as flow signals can persist in an inactive myopic CNV [39-41]. Therefore, activity assessment should be evaluated with clinical examination and multi-modal imaging, including structural OCT with or without FA. Motion or image artifacts and segmentation errors may further complicate its interpretation. Therefore, it is still recommended to complement SD-OCT and FFA to increase diagnostic accuracy and monitoring of the disease activity.

The imaging features of various stages of myopic CNV are summarized in Table 13.2. 
Table 13.2 Imaging characteristics of the different phases of myopic choroidal neovascularization

\begin{tabular}{l|l|l|l|l}
\hline Phase & Fundus appearance & $\begin{array}{l}\text { Fluorescein } \\
\text { angiography }\end{array}$ & $\begin{array}{l}\text { Indocyanine } \\
\text { green } \\
\text { angiography }\end{array}$ & $\begin{array}{l}\text { Optical coherence } \\
\text { tomography }\end{array}$ \\
\hline Active & $\begin{array}{l}\text { Small grayish } \\
\text { subretinal lesion at } \\
\text { or near the fovea, } \\
\text { with or without } \\
\text { hemorrhage }\end{array}$ & $\begin{array}{l}\text { Early } \\
\text { hyperfluorescence } \\
\text { increasing in size } \\
\text { and intensity with } \\
\text { time }\end{array}$ & $\begin{array}{l}\text { Late } \\
\text { hyperflu- } \\
\text { orescence }\end{array}$ & $\begin{array}{l}\text { Ill-defined subretinal } \\
\text { hyper-reflective lesion with } \\
\text { or without subretinal fluid }\end{array}$ \\
\hline Scar & $\begin{array}{l}\text { Grayish white, } \\
\text { sometimes } \\
\text { pigmented spot. } \\
\text { Absence of } \\
\text { hemorrhage }\end{array}$ & $\begin{array}{l}\text { Early } \\
\text { hyperfluorescence } \\
\text { decreasing in } \\
\text { intensity with } \\
\text { time, indicating } \\
\text { fluorescein } \\
\text { staining of } \\
\text { subretinal scar }\end{array}$ & $\begin{array}{l}\text { Hypoflu- } \\
\text { orescence }\end{array}$ & $\begin{array}{l}\text { Subretinal hyper-reflective } \\
\text { lesion with well-demarcated } \\
\text { margins }\end{array}$ \\
\hline Atrophic & $\begin{array}{l}\text { Well-demarcated } \\
\text { whitish lesion } \\
\text { centered on fovea. } \\
\text { Absence of } \\
\text { hemorrhage }\end{array}$ & Hypofluorescence & $\begin{array}{l}\text { Hypoflu- } \\
\text { orescence }\end{array}$ & $\begin{array}{l}\text { Absence of RPE-Bruch's } \\
\text { membrane-choriocapillaris } \\
\text { complex with } \\
\text { hypertransmission of signal } \\
\text { into the underlying sclera and } \\
\text { retro-orbital fat }\end{array}$ \\
\hline
\end{tabular}

\subsection{Differential Diagnosis}

There are several differential diagnoses that must be excluded from myopic CNV.

\subsubsection{Macular Hemorrhage Secondary to Lacquer Cracks (Fig. 13.2)}

In individuals with macular hemorrhage, it is critical to differentiate eyes with myopic CNV from those with simple hemorrhage associated with lacquer cracks (Fuch's hemorrhage). Eyes with Fuch's hemorrhage secondary to lacquer cracks tend to have better prognosis than myopic CNV and do not require anti-VEGF therapy [44]. In cases with thick blood, the myopic CNV may not be visible even in FA or OCTA due to masking. In these cases, late phases of ICGA will be able to visualize the myopic CNV if it is present [20].

\subsubsection{Inflammatory CNV}

Punctate inner choroidopathy (PIC) with or without secondary CNV may present with OCT appearance similar to that of myopic CNV. The clinical manifestation 

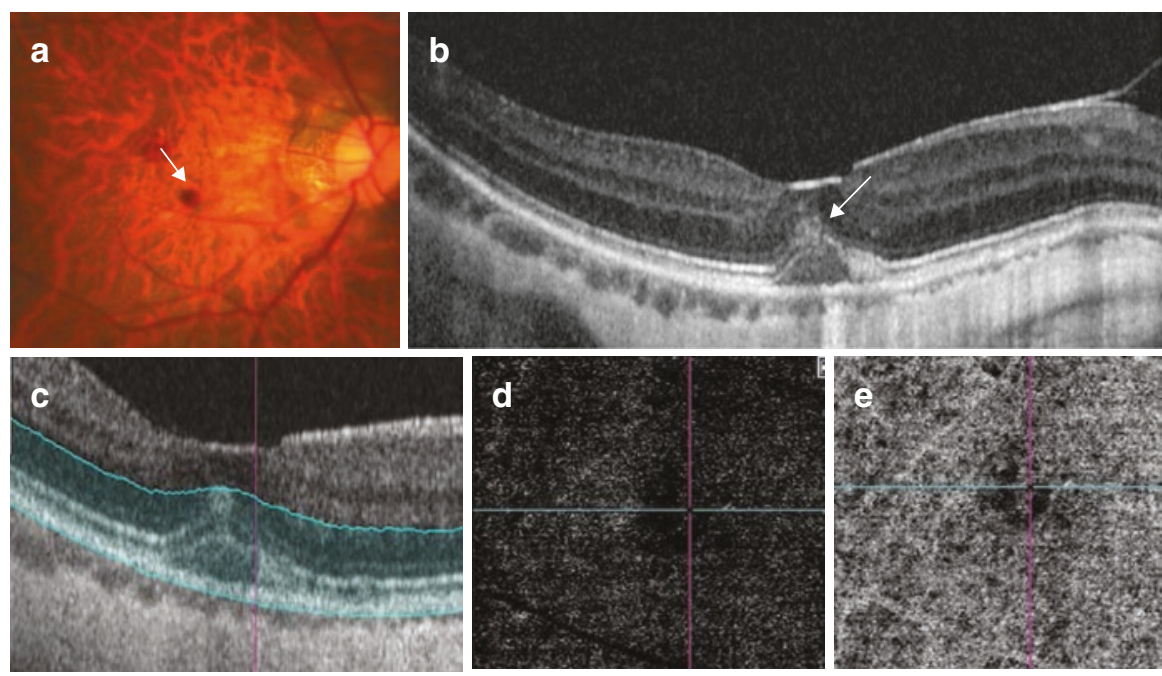

Fig. 13.2 A 51-year-old highly myopic male with lacquer crack hemorrhage. (a) Fundus photo shows a red spot suggestive of subretinal hemorrhage (white arrow). (b) Optical coherence tomographic scan shows a separation between the RPE and the underlying Bruch's membrane in the subfoveal position (white arrow head), with hyper-reflectivity in the subretinal space (white arrow) corresponding to the area of subretinal hemorrhage. Optical coherence tomographic angiography of the region of interest (c) shows no flow signals suggestive of choroidal neovascularization in the outer retinal slab (d) or the choriocapillaris slab (e)

of punctate inner choroidopathy differs from myopic $\mathrm{CNV}$, with characteristic creamy yellow-white lesions located at the RPE and inner choroid. A prospective series revealed that PIC lesions go through a five-stage evolution process with differing SD-OCT findings at each stage: choroidal infiltration (stage I: mostly normal but can present with hyper-reflective fine spots within the outer nuclear layer), formation of sub-RPE nodules (stage II: focal elevation of RPE with corresponding ellipsoid zone disruption), chorioretinal nodules (stage III: nodule that breaks through the RPE and progresses towards and replaces the photoreceptor layer that eventually domes the outer plexiform layer (OPL)), regression (stage IV: noted to begin from the apex towards the choroid and with herniation of the OPL and inner retina through the RPE break) and retinal herniation (stage V: sagging of the OPL and inner retina with loss of photoreceptor layer and RPE proliferation that relieves the retinal hernia) [45]. Of these various stages, only stage III may ostensibly be misdiagnosed as myopic CNV. The use of OCTA and its ability to identify vascular network can be particularly useful in this instance to distinguish myopic CNV from PIC as inflammatory lesions do not manifest vascular flow signals [46]. Unlike myopic CNV, the late phases of ICGA would reveal multiple areas of hypercyanescence in punctate inner choroidopathy [47]. 


\subsubsection{Dome-Shaped Maculopathy with Serous Detachment}

Dome-shaped maculopathy (DSM) is characterized by an inward bulge within the chorioretinal posterior concavity of the eye in the macular area [48, 49]. Serous foveal detachment is a complication of DSM that has been postulated to be related to the abnormal curvature of the macula [50]. On FFA, DSM with serous retinal detachment can be distinguished from myopic CNV where it may be associated with pinpoint leakage. On ICGA, it presents as punctate hypercyanescent spots [51]. The absence of macular hemorrhage, with the characteristic dome-shaped profile of the macula visualized on OCT, and the leakage of dye in later frames help differentiate this entity from myopic CNV.

\subsection{Management}

\subsubsection{Anti-Vascular Endothelial Growth Factor Drugs}

Prior to the advent of anti-VEGF therapy, the main treatment options for myopic CNV were limited to thermal laser photocoagulation [52] and photodynamic therapy with verteporfin (vPDT) [53, 54]. These treatments had limited efficacy in improving vision significantly and have now largely been relegated to the annals of history by the anti-vascular endothelial growth factor (anti-VEGF) therapy [55].

\subsection{Ranibizumab}

Ranibizumab is a Fab fragment of humanized monoclonal antibody against all isoforms of VEGF-A, and it was the first anti-VEGF agent to be FDA approved for the treatment of myopic CNV. The strongest evidence of anti-VEGF use for myopic CNV comes from two large multi-centered, double-masked, randomized, controlled clinical trials $[56,57]$. The RADIANCE study $(n=277)$ was a 12 -month, phase III, randomized, double-masked, multicenter study comparing the efficacy and safety of intravitreal ranibizumab $0.5 \mathrm{mg}$ versus vPDT in patients with myopic CNV [56]. This trial demonstrated the superiority of ranibizumab $0.5 \mathrm{mg}$, with a mean visual acuity gain of 10.5-10.6 letters compared to 2.2 letters with vPDT at 3 months and maintained through 12 months. The study further compared two retreatment protocols and showed that the disease activity guided retreatment based on OCT could achieve similar visual outcomes with a lower median number of injections (2.0) compared to retreatment according to visual acuity stabilization (4.0 injections). The RADIANCE study confirmed the results of the REPAIR trial, a phase II prospective, open-label, multicenter study of intravitreal ranibizumab $0.5 \mathrm{mg}$ in myopic CNV in 65 eyes. In this study, a mean visual gain of 13.8 letters was achieved with a mean of 3.6 ranibizumab injections over 12 months in a cohort of 
treatment-naïve patients with myopic CNV [58]. These trials were performed in predominantly Caucasian populations. To support the use of ranibizumab for Asian patients with myopic CNV, the BRILLIANCE study was conducted with a design similar to the RADIANCE study. This was a 12-month, double-masked trial in which study participants with myopic CNV were randomized into one of three treatment groups: ranibizumab guided by visual acuity stabilization criteria (group $1, n=182$ ), ranibizumab guided by disease activity (group $2, n=184$ ) and vPDT followed by ranibizumab/vPDT/both treatments at month 3 , guided by the disease activity (group 3, $n=91$ ) [55]. Findings from the BRILLIANCE study corroborated with those from the RADIANCE study. Both ranibizumab arms experienced significantly better visual acuity gains at 3 months compared to the vPDT arm (Group I/ II: $+9.5 /+9.8$ letters vs. Group III: +4.5 letters; both $P<0.001$ ), and ranibizumab treatment guided by disease activity was noninferior to treatment guided by visual acuity stabilization, achieving similar visual acuity outcomes with a median of three and four injections over 12 months, respectively. These results confirmed the efficacy of ranibizumab for the treatment of myopic CNV in Asian patients.

In a large post-marketing surveillance study of ranibizumab for the treatment of Japanese patients with myopic CNV $(n=318)$ over a 12-month observation period, ranibizumab was found to be safe (incidence of $0.6 \%$ and $0.3 \%$ of adverse drug reactions and serious adverse events, respectively) and effective with a low number of injections needed for the therapeutic effect (median injection number of 1 and $52.2 \%$ requiring only 1 injection) [59].

\subsection{Aflibercept}

Aflibercept is a recombinant human fusion protein that acts as a soluble decoy receptor for VEGF family members VEGF-A, VEGF-B and placental growth factor, preventing these ligands from binding to, and activating, their receptors. The MYRROR trial was a 48-week, phase III, multicenter, randomized, double-masked, sham-controlled study investigating the efficacy and safety of intravitreal aflibercept $2 \mathrm{mg}$ for the treatment of myopic CNV [57]. Patients treated with intravitreal aflibercept $(n=91)$ achieved a mean visual gain of 12 letters compared to a 2-letter loss in the sham group $(n=31)$. The mean number of injections was low in this study (4.2 injections over 48 weeks). Significant improvement in the quality of life (National Eye Institute Visual Function Questionnaire 25 and EuroQol-5 Dimension score) was also demonstrated in patients treated with aflibercept.

\subsection{Bevacizumab}

Bevacizumab was the first angiogenesis inhibitor to be approved for clinical use, initially for the treatment of metastatic colorectal cancer. Since then, it has been used as an open-label drug and a lower cost option for the treatment of choroidal neovascularization, including myopic CNV. There is a lack of randomized 
controlled trials assessing the efficacy of bevacizumab in the treatment of myopic $\mathrm{CNV}$, but many clinical case series have reported significant visual gains ranging from 5 to 20 letters with the open-label use of bevacizumab [60-64]. Long-term studies have also demonstrated maintenance of visual gains for up to 4 years after the initial treatment $[52,65]$.

\subsection{Conbercept}

Conbercept is a recombinant fusion protein containing the second Ig-like domain of VEGFR-1, the third and fourth Ig-like domains of VEGFR-2 and a human IgG Fc fragment, with binding affinity to VEGF and placental growth factor (PIGF) [66]. There are no prospective interventional trials on the use of conbercept for myopic CNV. Yan et al. performed a retrospective analysis of 42 consecutive eyes with myopic CNV treated with three loading doses of conbercept at monthly intervals, followed by as-needed injections based on monthly follow-up visits till month 12 . BCVA improved from $0.67 \log$ MAR at baseline to 0.32 at 12 months, with $71.4 \%$ achieving three lines or more improvement at final follow-up with a mean of 3.76 injections [67].

\subsection{Factors Related to Treatment Outcomes}

As previously mentioned, older age, subfoveal location of CNV, larger lesion size and poorer presenting visual acuity are poor prognostic factors for myopic CNV [8, $25,68]$. In addition, subretinal hemorrhage, duration of CNV and previous photodynamic therapy were found to confer a poorer prognosis after treatment [68]. Similarly, older age, larger CNV size and greater central macular thickness were factors associated with the need for retreatment [69-71]. Thinner choroid and lacquer cracks were also found to be associated with the need for a higher number of intravitreal injections [71].

The presence of vitreomacular abnormalities, in particular epiretinal membrane (ERM), is common in high myopes. ERM often coexists with myopic CNV. The presence of ERM has been shown to hamper visual gains after treatment of myopic CNV with ranibizumab compared to eyes without ERM (visual stabilization from a baseline of $0.3-0.4$ compared to improvement from 0.3 to $0.1, p=0.008$ ). The coexistence of ERM with myopic CNV neither influenced the median number of injections (3) nor the reduction in central foveal thickness [72]. As regards the myopic macular retinoschisis (MRS), a post hoc analysis of the RADIANCE trial showed that eyes with MRS received more injections $(5.8 \pm 2.1$ vs $4.0 \pm 2.9 ; P=0.0001)$, had slower visual gain at 3 months $(+2.8$ letters vs +12.3 letters $)$ and poorer visual outcomes at 12 months $(+7.1$ letters vs +14.4 letters $)$ than eyes without MRS [73]. Post hoc analysis further evaluated whether baseline myopic macular degeneration (MMD) influenced the treatment outcomes in 115 eyes. Change in BCVA from baseline to week 48 was not significantly different between eyes with mild MMD 
(META-PM category 1-2) and eyes with severe MMD (META-PM category 1-2) $(+13.5$ letters vs +12.4 letters, $p=0.83)$, and were achieved with a similar number of injections (3.9 vs 5.4, $p=0.23$ ) [74].

\subsection{Recurrence}

The recurrence rate of myopic CNV is generally low, with most recurrences occurring during the first year. Yang et al. reported a recurrence rate of $23.3 \%$ in a retrospective series of 103 eyes of 89 consecutive patients with subfoveal myopic CNV, followed over 2 years. $72.7 \%$ of recurrences occurred in the first year of treatment. Baseline CNV size was found to be a significant prognostic factor for recurrence on multivariate analysis [71]. In the post-RADIANCE observation study (1248 months), only $10 \%$ of eyes experienced a recurrence [75]. These findings reinforce the importance of monitoring for recurrences in the first year of treatment.

\subsection{Treatment Regimen and Follow-Up}

Once active myopic CNV is diagnosed, prompt treatment with intravitreal antiVEGF therapy should be administered as soon as possible [56, 58]. Current evidence suggests that a pro re nata $(\mathrm{PRN})$ regimen without a loading phase can be considered in most patients. Patients should be monitored monthly with OCT and treatment administered until cessation of the disease activity on OCT or visual stabilization. FA may be performed to confirm inactive disease before stopping treatment, especially if there are uncertainties regarding activity based on OCT. Thereafter, review can be progressively lengthened on an individualized basis if no further activity is observed in the first year to monitor for recurrence or development of myopic $\mathrm{CNV}$ in the fellow eye. After the first year of treatment, patients without recurrence can have their visit interval prolonged to 6 months. Patients should be advised to return if vision drops or metamorphopsia recurs [3].

\subsection{Long-Term Outcomes}

Although anti-VEGF therapy for myopic CNV has demonstrated remarkable short- and mid-term efficacy, longer term visual outcomes are generally less favorable, with most studies reporting a gradual decline back to baseline visual acuity [60, 61, 75-79]. Onishi et al. reported the 5-year outcomes of 51 patients who received treatment with ranibizumab for myopic CNV. Mean baseline BCVA (0.38 $\log$ MAR) was significantly improved at 1 year $(0.27 \log$ MAR $)$ but not in the subsequent years $(0.31,0.35$ and $0.32 \log$ MAR at 2,4 and 5 years, respectively). Sarao et al. reported similar findings in a prospective interventional study with mean BCVA improvement of -0.13 at 24 months in 101 eyes with myopic CNV treated with bevacizumab and an increase in the area of chorioretinal atrophy in 
the same period [61]. In contrast, the long-term visual outcomes of 41 patients who had completed the RADIANCE trial were shown to be sustained up to 48 months post initiation of treatment. Mean visual gain from baseline $(56.5 \pm 12.1$ letters) was significant up to 48 months $(+16.3 \pm 18.7, n=16, p=0.0034)$. Of the 16 patients who completed 48 months of follow-up, $63 \%$ gained $\geq 10$ letters and $13 \%$ lost $\geq 10$ letters. Over the post-RADIANCE observation period (months $12-48), 83 \%$ of patients required no further treatment and $10 \%$ experienced recurrences [75].

Similar results were reported in Caucasian patients with myopic CNV $(n=40)$ treated with intravitreal ranibizumab: baseline visual acuity improved from 55.4 letters to 63.4 letters at 3 years $(p=0.039)$ and $35 \%$ gained 15 letters or more at the final follow-up, achieved with a mean of 4.1 injections in the first year, 2.4 in the second year and 1.1 in the third year [76]. A longer term follow-up study in Caucasian eyes treated with bevacizumab or ranibizumab found that visual gains could be maintained at $3(+9.0$ letters, $n=52), 4(+9.0$ letters, $n=28)$ and 5 years (+9.8 letters, $n=13$ ) [77]. A 5-year outcome study by the PAN-American Collaborative Retina Study Group with intravitreal bevacizumab $(n=33)$ reported a significant decline in visual acuity from $0.65 \pm 0.33 \log$ MAR at baseline to $0.73 \pm 0.50 \log$ MAR units at final follow-up $(p=0.003)$ [80].

In the longest follow-up study to date, Pastore et al. reported on the visual outcomes of 17 eyes with myopic $\mathrm{CNV}$, treated with ranibizumab according to a strict pro re nata regimen over 9 years. Mean visual acuity was significantly improved from baseline (56.2 \pm 13.5 letters $)$ at $1(69.7 \pm 12.2$ letters $)$ and 2 years $(69.9 \pm 12.8$ letters) post treatment initiation, but gradually receded towards baseline at 9 years ( $57.4 \pm 17.7$ letters). Only $11.8 \%$ of eyes lost 3 lines or more, while $17.7 \%$ maintained 3 lines or more gain in vision at 9 years, achieved with a mean of $1.24 \pm 1.70$ injections per year (range 2-25) [78]. Despite a loss of visual gains, these results demonstrate a considerably superior visual prognosis for patients with myopic CNV than patients with $\mathrm{CNV}$ secondary to age-related macular degeneration over the long term [81, 82].

Myopic CNV-related chorioretinal atrophy (CRA) is the major culprit for the loss of visual gain over the long term. Ohno Matsui et al. found that the macular atrophy developing after myopic CNV may be related to rupture of Bruch's membrane. This defect in Bruch's membrane may continue to expand in spite of adequate treatment of myopic CNV, leading to macular atrophy and loss of vision [16]. This point was demonstrated in a 5-year outcome study of eyes with myopic CNV treated with intravitreal ranibizumab $(n=51)$, in which visual stability was achieved (baseline best corrected visual acuity 20/49 compared to 20/42) at 5 years, where good visual outcome was shown to be significantly associated with a lack of enlargement of CNVrelated macular atrophy, in addition to better baseline visual acuity and a lower number of injections [79]. These outcomes were achieved with a mean of 1.6 injections over 5 years, and two-thirds received only 1 injection. Another study by Ohno Matsui's group observed similar findings in patients treated with bevacizumab $(n=36)$. Visual acuity improved significantly from a baseline of $0.5 \log$ MAR to 0.31 and 0.39 at years 2 and 4 , respectively, but not at 6 years $(0.45)$, achieved with a mean 
of 1.78 injections. Again, visual outcomes at 6 years were correlated with the size of CNV-related macular atrophy, as well as baseline visual acuity and CNV size. Further, in a long-term (mean follow-up $80.6 \pm 28.0$ months) retrospective review of 54 eyes with myopic CNV treated with photodynamic therapy and/or intravitreal ranibizumab and eyes with myopic maculopathy alone, the progression of macular atrophy was significantly greater in myopic CNV eyes compared to the eyes with only myopic maculopathy. The risk of progression was related to age, degree of myopia and presence of staphyloma, but not the type of treatment [83].

\subsection{Conclusions}

Myopic CNV is a sight-threatening complication of pathologic myopia that, fortunately, has an effective treatment in the form of anti-VEGF injections. Early detection, accurate diagnosis with multimodal imaging, early initiation of treatment, and careful post-treatment monitoring are key to achieving good treatment outcomes. Although FFA and OCT remain the gold standard for diagnosis, OCTA is emerging as a good adjunct imaging modality to screen for the presence of neovascular networks in patients with suspected myopic CNV. Anti-VEGF therapy has been shown to be efficacious and safe with a low treatment burden. Finally, long-term visual outcomes remain less favorable, largely due to the development of chorioretinal atrophy around the regressed CNV. Therapeutic strategies to prevent the enlargement of CNV-related atrophy should form the focus of future research for the treatment of myopic CNV.

\section{References}

1. Cohen SY, Laroche A, Leguen Y, Soubrane G, Coscas GJ. Etiology of choroidal neovascularization in young patients. Ophthalmology. 1996;103(8):1241-4.

2. Yoshida T, Ohno-Matsui K, Yasuzumi K, et al. Myopic choroidal neovascularization: a 10-year follow-up. Ophthalmology. 2003;110(7):1297-305.

3. Ohno-Matsui K, Ikuno Y, Lai TYY, Gemmy Cheung CM. Diagnosis and treatment guideline for myopic choroidal neovascularization due to pathologic myopia. Prog Retin Eye Res. 2018;63:92-106.

4. Cheung CMG, Arnold JJ, Holz FG, et al. Myopic choroidal neovascularization: review, guidance, and consensus statement on management. Ophthalmology. 2017;124(11): 1690-711.

5. Ohno-Matsui K, Lai TY, Lai CC, Cheung CM. Updates of pathologic myopia. Prog Retin Eye Res. 2016;52:156-87.

6. Avila MP, Weiter JJ, Jalkh AE, Trempe CL, Pruett RC, Schepens CL. Natural history of choroidal neovascularization in degenerative myopia. Ophthalmology. 1984;91(12): 1573-81.

7. Neelam K, Cheung CM, Ohno-Matsui K, Lai TY, Wong TY. Choroidal neovascularization in pathological myopia. Prog Retin Eye Res. 2012;31(5):495-525.

8. Wong TY, Ferreira A, Hughes R, Carter G, Mitchell P. Epidemiology and disease burden of pathologic myopia and myopic choroidal neovascularization: an evidence-based systematic review. Am J Ophthalmol. 2014;157(1):9-25.e12.

9. Curtin BJ, Karlin DB. Axial length measurements and fundus changes of the myopic eye. I. The posterior fundus. Trans Am Ophthalmol Soc. 1970;68:312-34. 
10. Grossniklaus HE, Green WR. Pathologic findings in pathologic myopia. Retina. 1992;12(2):127-33.

11. Hayashi K, Ohno-Matsui K, Shimada N, Moriyama M, Kojima A, Hayashi W, Yasuzumi K, Nagaoka N, Saka N, Yoshida T, Tokoro T, Mochizuki M. Long-term pattern of progression of myopic maculopathy: a natural history study. Ophthalmology. 2010;117(8):1595-611. 1611.e1-4.

12. Ohno-Matsui K, Yoshida T, Futagami S, et al. Patchy atrophy and lacquer cracks predispose to the development of choroidal neovascularisation in pathological myopia. Br J Ophthalmol. 2003;87(5):570-3.

13. Tokoro T. Atlas of posterior fundus changes in pathologic myopia. Tokyo: Springer; 1998.

14. Ohno-Matsui K. What is the fundamental nature of pathologic myopia? Retina. 2017;37(6):1043-8.

15. Ohno-Matsui K, Yoshida T. Myopic choroidal neovascularization: natural course and treatment. Curr Opin Ophthalmol. 2004;15(3):197-202.

16. Ohno-Matsui K, Jonas JB, Spaide RF. Macular Bruch membrane holes in choroidal neovascularization-related myopic macular atrophy by swept-source optical coherence tomography. Am J Ophthalmol. 2016;162:133-139.e131.

17. Shimada N, Ohno-Matsui K, Yoshida T, Futagami S, Tokoro T, Mochizuki M. Development of macular hole and macular retinoschisis in eyes with myopic choroidal neovascularization. Am J Ophthalmol. 2008;145(1):155-61.

18. Cheung CM, Loh BK, Li X, et al. Choroidal thickness and risk characteristics of eyes with myopic choroidal neovascularization. Acta Ophthalmol. 2013;91(7):e580-1.

19. Ikuno Y, Jo Y, Hamasaki T, Tano Y. Ocular risk factors for choroidal neovascularization in pathologic myopia. Invest Ophthalmol Vis Sci. 2010;51(7):3721-5.

20. Kim YM, Yoon JU, Koh HJ. The analysis of lacquer crack in the assessment of myopic choroidal neovascularization. Eye. 2011;25(7):937-46.

21. Ng WY, Ting DS, Agrawal R, et al. Choroidal structural changes in myopic choroidal neovascularization after treatment with antivascular endothelial growth factor over 1 year. Invest Ophthalmol Vis Sci. 2016;57(11):4933-9.

22. Tong JP, Chan WM, Liu DT, et al. Aqueous humor levels of vascular endothelial growth factor and pigment epithelium-derived factor in polypoidal choroidal vasculopathy and choroidal neovascularization. Am J Ophthalmol. 2006;141(3):456-62.

23. Yamamoto Y, Miyazaki D, Sasaki S, et al. Associations of inflammatory cytokines with choroidal neovascularization in highly myopic eyes. Retina. 2015;35(2):344-50.

24. Long Q, Ye J, Li Y, Wang S, Jiang Y. C-reactive protein and complement components in patients with pathological myopia. Optom Vis Sci. 2013;90(5):501-6.

25. Wong TY, Ohno-Matsui K, Leveziel N, et al. Myopic choroidal neovascularisation: current concepts and update on clinical management. Br J Ophthalmol. 2015;99(3):289-96.

26. Curtin BJ, Karlin DB. Axial length measurements and fundus changes of the myopic eye. Am J Ophthalmol. 1971;71(1 Pt 1):42-53.

27. Noble KG, Carr RE. Pathologic myopia. Ophthalmology. 1982;89(9):1099-100.

28. Lloyd RI. Clinical studies of the myopic macula. Trans Am Ophthalmol Soc. 1953;51:273-84.

29. Seko Y, Fujikura H, Pang J, Tokoro T, Shimokawa H. Induction of vascular endothelial growth factor after application of mechanical stress to retinal pigment epithelium of the rat in vitro. Invest Ophthalmol Vis Sci. 1999;40(13):3287-91.

30. Young TL. Dissecting the genetics of human high myopia: a molecular biologic approach. Trans Am Ophthalmol Soc. 2004;102:423-45.

31. Leveziel N, Yu Y, Reynolds R, et al. Genetic factors for choroidal neovascularization associated with high myopia. Invest Ophthalmol Vis Sci. 2012;53(8):5004-9.

32. Wakabayashi T, Ikuno Y. Choroidal filling delay in choroidal neovascularisation due to pathological myopia. Br J Ophthalmol. 2010;94(5):611-5.

33. Dimitrova G, Tamaki Y, Kato S, Nagahara M. Retrobulbar circulation in myopic patients with or without myopic choroidal neovascularisation. Br J Ophthalmol. 2002;86(7):771-3.

34. Ohno-Matsui K, Kawasaki R, Jonas JB, et al. International photographic classification and grading system for myopic maculopathy. Am J Ophthalmol. 2015;159(5):877-883.e877.

35. Lai TY, Cheung CM. Myopic choroidal neovascularization: diagnosis and treatment. Retina. 2016;36(9):1614-21. 
36. Cheung CMG, Lai TYY, Ruamviboonsuk P, et al. Polypoidal choroidal vasculopathy: definition, pathogenesis, diagnosis, and management. Ophthalmology. 2018;125(5):708-24.

37. Soomro T, Talks J, Medscape. The use of optical coherence tomography angiography for detecting choroidal neovascularization, compared to standard multimodal imaging. Eye. 2018;32(4):661-72.

38. Jia Y, Bailey ST, Wilson DJ, et al. Quantitative optical coherence tomography angiography of choroidal neovascularization in age-related macular degeneration. Ophthalmology. 2014;121(7):1435-44.

39. Bruyere E, Miere A, Cohen SY, et al. Neovascularization secondary to high myopia imaged by optical coherence tomography angiography. Retina. 2017;37(11):2095-101.

40. Miyata M, Ooto S, Hata M, et al. Detection of myopic choroidal neovascularization using optical coherence tomography angiography. Am J Ophthalmol. 2016;165:108-14.

41. Querques L, Giuffre C, Corvi F, et al. Optical coherence tomography angiography of myopic choroidal neovascularisation. Br J Ophthalmol. 2017;101(5):609-15.

42. Sayanagi K, Ikuno Y, Uematsu S, Nishida K. Features of the choriocapillaris in myopic maculopathy identified by optical coherence tomography angiography. $\mathrm{Br} \mathrm{J}$ Ophthalmol. 2017;101(11):1524-9.

43. Wong CW, Teo YCK, Tsai STA, et al. Characterization of the choroidal vasculature in myopic maculopathy with optical coherence tomographic angiography. Retina. 2018. https://doi. org/10.1097/IAE.0000000000002233.

44. Moriyama M, Ohno-Matsui K, Shimada N, et al. Correlation between visual prognosis and fundus autofluorescence and optical coherence tomographic findings in highly myopic eyes with submacular hemorrhage and without choroidal neovascularization. Retina. 2011;31(1):74-80.

45. Zhang X, Zuo C, Li M, Chen H, Huang S, Wen F. Spectral-domain optical coherence tomographic findings at each stage of punctate inner choroidopathy. Ophthalmology. 2013;120(12):2678-83.

46. Tan ACS, Tan GS, Denniston AK, et al. An overview of the clinical applications of optical coherence tomography angiography. Eye. 2018;32(2):262-86.

47. Spaide RF, Goldberg N, Freund KB. Redefining multifocal choroiditis and panuveitis and punctate inner choroidopathy through multimodal imaging. Retina. 2013;33(7):1315-24.

48. Gaucher D, Erginay A, Lecleire-Collet A, et al. Dome-shaped macula in eyes with myopic posterior staphyloma. Am J Ophthalmol. 2008;145(5):909-14.

49. Caillaux V, Gaucher D, Gualino V, Massin P, Tadayoni R, Gaudric A. Morphologic characterization of dome-shaped macula in myopic eyes with serous macular detachment. Am J Ophthalmol. 2013;156(5):958-967.e951.

50. Ellabban AA, Tsujikawa A, Matsumoto A, et al. Three-dimensional tomographic features of dome-shaped macula by swept-source optical coherence tomography. Am J Ophthalmol. 2013;155(2):320-328.e322.

51. Viola F, Dell'Arti L, Benatti E, et al. Choroidal findings in dome-shaped macula in highly myopic eyes: a longitudinal study. Am J Ophthalmol. 2015;159(1):44-52.

52. Virgili G, Menchini F. Laser photocoagulation for choroidal neovascularisation in pathologic myopia. Cochrane Database Syst Rev. 2005;4:CD004765.

53. Blinder KJ, Blumenkranz MS, Bressler NM, et al. Verteporfin therapy of subfoveal choroidal neovascularization in pathologic myopia: 2-year results of a randomized clinical trial--VIP report no. 3. Ophthalmology. 2003;110(4):667-73.

54. Verteporfin in Photodynamic Therapy Study G. Photodynamic therapy of subfoveal choroidal neovascularization in pathologic myopia with verteporfin. 1-year results of a randomized clinical trial--VIP report no. 1. Ophthalmology. 2001;108(5):841-52.

55. Chen Y, Sharma T, Li X, et al. Ranibizumab versus verteporfin photodynamic therapy in asian patients with myopic choroidal neovascularization: brilliance, a 12-month, randomized, double-masked study. Retina. 2018. https://doi.org/10.1097/IAE.0000000000002292.

56. Wolf S, Balciuniene VJ, Laganovska G, et al. RADIANCE: a randomized controlled study of ranibizumab in patients with choroidal neovascularization secondary to pathologic myopia. Ophthalmology. 2014;121(3):682-692.e682. 
57. Ikuno Y, Ohno-Matsui K, Wong TY, et al. Intravitreal aflibercept injection in patients with myopic choroidal neovascularization: the MYRROR study. Ophthalmology. 2015;122(6):1220-7.

58. Tufail A, Narendran N, Patel PJ, et al. Ranibizumab in myopic choroidal neovascularization: the 12-month results from the REPAIR study. Ophthalmology. 2013;120(9):19441945.e1941.

59. Ohno-Matsui K, Suzaki M, Teshima R, Okami N. Real-world data on ranibizumab for myopic choroidal neovascularization due to pathologic myopia: results from a post-marketing surveillance in Japan. Eye. 2018;32(12):1871-8.

60. Kasahara K, Moriyama M, Morohoshi K, et al. Six-year outcomes of intravitreal bevacizumab for choroidal neovascularization in patients with pathologic myopia. Retina. 2017;37(6):1055-64.

61. Sarao V, Veritti D, Macor S, Lanzetta P. Intravitreal bevacizumab for choroidal neovascularization due to pathologic myopia: long-term outcomes. Graefes Arch Clin Exp Ophthalmol. 2016;254(3):445-54.

62. Baba T, Kubota-Taniai M, Kitahashi M, Okada K, Mitamura Y, Yamamoto S. Two-year comparison of photodynamic therapy and intravitreal bevacizumab for treatment of myopic choroidal neovascularisation. Br J Ophthalmol. 2010;94(7):864-70.

63. Ikuno Y, Nagai Y, Matsuda S, et al. Two-year visual results for older Asian women treated with photodynamic therapy or bevacizumab for myopic choroidal neovascularization. Am J Ophthalmol. 2010;149(1):140-6.

64. Gharbiya M, Cruciani F, Parisi F, Cuozzo G, Altimari S, Abdolrahimzadeh S. Long-term results of intravitreal bevacizumab for choroidal neovascularisation in pathological myopia. Br J Ophthalmol. 2012;96(8):1068-72.

65. Peiretti E, Vinci M, Fossarello M. Intravitreal bevacizumab as a treatment for choroidal neovascularisation secondary to myopia: 4-year study results. Can J Ophthalmol. 2012; 47(1):28-33.

66. Wu Z, Zhou P, Li X, et al. Structural characterization of a recombinant fusion protein by instrumental analysis and molecular modeling. PLoS One. 2013;8(3):e57642.

67. Yan M, Huang Z, Lian HY, Song YP, Chen X. Conbercept for treatment of choroidal neovascularization secondary to pathologic myopia. Acta Ophthalmol. 2018. https://doi.org/10.1111/ aos.13632.

68. Wang J, Kang Z. Summary of prognostic factors for choroidal neovascularization due to pathological myopia treated by intravitreal bevacizumab injection. Graefes Arch Clin Exp Ophthalmol. 2012;250(12):1717-23.

69. Iacono P, Battaglia Parodi M, Selvi F, et al. Factors influencing visual acuity in patients receiving anti-vascular endothelial growth factor for myopic choroidal neovascularization. Retina. 2017;37(10):1931-41.

70. Ng DS, Kwok AK, Tong JM, Chan CW, Li WW. Factors influencing need for retreatment and long-term visual outcome after intravitreal bevacizumab for myopic choroidal neovascularization. Retina. 2015;35(12):2457-68.

71. Yang HS, Kim JG, Kim JT, Joe SG. Prognostic factors of eyes with naive subfoveal myopic choroidal neovascularization after intravitreal bevacizumab. Am J Ophthalmol. 2013;156(6):1201-1210.e1202.

72. Iacono P, Battaglia Parodi M, Iuliano L, Bandello F. How vitreomacular interface modifies the efficacy of anti-Vegf therapy for myopic choroidal neovascularization. Retina. 2018;38(1):84-90.

73. Ceklic L, Munk MR, Wolf-Schnurrbusch U, Gekkieva M, Wolf S. Visual acuity outcomes of ranibizumab treatment in pathologic myopic eyes with macular retinoschisis and choroidal neovascularization. Retina. 2017;37(4):687-93.

74. Gemmy Chui Ming Cheung KO-M, Tien Yin Wong, Tummy Li, Friedrich Asmus, Sergio L, et al. Influence of myopic macular degeneration (MMD) severity on treatment outcomes of myopic choroidal neovascularization $(\mathrm{mCNV})$ in the MYRROR Study. In: Presented at the American Academy of Ophthalmology (AAO) Congress Chicago, IL 2016. 
75. Tan NW, Ohno-Matsui K, Koh HJ, et al. Long-term outcomes of ranibizumab treatment of myopic choroidal neovascularization in East-Asian patients from the radiance study. Retina. 2017;38(11):2228-38.

76. Franqueira N, Cachulo ML, Pires I, et al. Long-term follow-up of myopic choroidal neovascularization treated with ranibizumab. Ophthalmologica. 2012;227(1):39-44.

77. Freitas-da-Costa P, Pinheiro-Costa J, Carvalho B, et al. Anti-VEGF therapy in myopic choroidal neovascularization: long-term results. Ophthalmologica. 2014;232(1):57-63.

78. Pastore MR, Capuano V, Bruyere E, et al. Nine-year outcome of ranibizumab monotherapy for choroidal neovascularization secondary to pathologic myopia. Ophthalmologica. 2018;239(2-3):133-42.

79. Onishi Y, Yokoi T, Kasahara K, et al. Five-year outcomes of intravitreal ranibizumab for choroidal neovascularization in patients with pathologic myopia. Retina. 2018. https://doi. org/10.1097/IAE.0000000000002164.

80. Chhablani J, Paulose RM, Lasave AF, et al. Intravitreal bevacizumab monotherapy in myopic choroidal neovascularisation: 5-year outcomes for the PAN-American Collaborative Retina Study Group. Br J Ophthalmol. 2018;102(4):455-9.

81. Rofagha S, Bhisitkul RB, Boyer DS, Sadda SR, Zhang K, Group S-US. Seven-year outcomes in ranibizumab-treated patients in anchor, marina, and horizon: a multicenter cohort study (SEVEN-UP). Ophthalmology. 2013;120(11):2292-9.

82. Maguire MG, Martin DF, Comparison of Age-related Macular Degeneration Treatments Trials Research G, et al. Five-year outcomes with anti-vascular endothelial growth factor treatment of neovascular age-related macular degeneration: the comparison of age-related macular degeneration treatments trials. Ophthalmology. 2016;123(8):1751-61.

83. Farinha CL, Baltar AS, Nunes SG, et al. Progression of myopic maculopathy after treatment of choroidal neovascularization. Ophthalmologica. 2014;231(4):211-20.

Open Access This chapter is licensed under the terms of the Creative Commons Attribution 4.0 International License (http://creativecommons.org/licenses/by/4.0/), which permits use, sharing, adaptation, distribution and reproduction in any medium or format, as long as you give appropriate credit to the original author(s) and the source, provide a link to the Creative Commons license and indicate if changes were made.

The images or other third party material in this chapter are included in the chapter's Creative Commons license, unless indicated otherwise in a credit line to the material. If material is not included in the chapter's Creative Commons license and your intended use is not permitted by statutory regulation or exceeds the permitted use, you will need to obtain permission directly from the copyright holder.

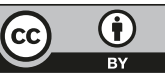

